\title{
School Children Knowledge Regarding Dental Hygiene.
}

\author{
Ms. Manveer Kaur* \\ Children are our most valuable natural resources" \\ Guide: Ms. Lalita Kumari (Principal cum Professor S.G.L. Nursing College, Jalandhar Punjab)
}

\begin{abstract}
School health education services are an economical and powerful means of raising standard of community health, especially for the future generations. School is considered as a best setting for the positive health and prevention of diseases, awakening health consciousness in which the child grows and develops. A pre-experimental study was conducted to assess the effectiveness of structured teaching programme on knowledge regarding dental hygiene among middle schoolchildren. The study was conducted in government schools of Jalandhar district, Punjab. Totally 60 students those who met the inclusion and exclusion criteria were selected by convenience sampling technique. A pre-test was taken by using structured questionnaire followed by structured teaching programme. After 7 days post-test was taken. The result of the post-test score revealed that the structured teaching programme had its impact on improving the level of knowledge regarding dental hygiene among middle school children. The overall mean score of pre-test was 14.91 with the S.D. 3.84, whereas in post-test the overall mean score of 23.01 with S.D. of 3.72. The t-test value was $-\mathbf{8 . 1 *}$ which is statistically significant at $p<0.005$ level of significance. After structured teaching programme $\mathbf{6 8 \%}$ students had average and 32\% had good level of knowledge and no one had poor level of knowledge regarding dental hygiene. The study finding implied that the education had a vital role in improving the knowledge of school children regarding dental hygiene.
\end{abstract}

\section{Introduction}

A child is a precious gift which has lots of potential within, which can be the best resource for nation if raised and moulded in good manner. Healthy children can become healthy citizen constituting a healthy nation. Healthy children are also successful learners. School age children represent about $25 \%$ of total population, so it indicates that health care of the school children can contribute to the overall health status of the country. Dental caries is the leading dental problem of children, $90 \%$ of all children have some tooth decay by 12 years of age. $95 \%$ of all cavities are caused by specific eating sugar habits like candies, ice-cream, canned juice which usually develop during early childhood as a result of changing life style. Dental diseases affecting the child are not same as affecting that adult. The target organs are the same like, teeth, gingival, but the etiopathogenesis are different because, primary dentition is morphologically different, food habits are different from that of adult and poor control over maintance of oral hygiene leads to common dental problems that include dental plaque, dental caries, malocclusion, gingivitis etc. Hence the importance of preventing dental caries is at the school age level is very essential.

\section{Need of the study}

School health is an important branch of community health. According to Elias M.J.et al. (1994), the school years are a time of increasing risk for negative health related outcomes. Hence, these groups develop cognitive, affective and behavioural changes which in turn can promote children's health and prevent health problems. Thus, the school remains a natural channel through which the health of the community can be improved with the children as the natural agent to change.

Today the child health is viewed as a holistic and positive component for the total development and health is essential for high quality of life for children. A healthful school environment therefore is necessary for the best emotional, social and personal health of the pupils. The ultimate aim of structured teaching programme is to bring a significant change in the knowledge and health behaviour of children and family.

According to WHO, aim of " Health for All by the year 2000" the global status for children, should be that $50 \%$ of children between the ages of 5 and 6 years will be caries free and at 12 years of age they should have 3 or fewer decayed, missing or filled teeth. In India caries is the commonest disease in school age, affecting 50-75\% of them. Children are suffering more from dental disease which is continuously increasing at a high rate due to lack of appropriate care and inadequate knowledge regarding Dental hygiene. Dental health is recognized as one of the vital need of the children. The school environment is more conducive to learning, hence dental health education and motivation shall be more effective.

\section{Ms. Manveer Kaur, Lecturer Child Health ( Paediatric) Nursing,}




\section{Statement of problem}

A pre-experimental study on the effectiveness of structured teaching programme on knowledge regarding Dental hygiene among middle school children in selected schools of Jalandhar district, Punjab, 2012.

Objectives

1. To assess the pre test knowledge of middle school children regarding Dental hygiene.

2. To plan and implement structured teaching programme regarding Dental hygiene among middle school children.

3. To assess post test knowledge of middle school children regarding Dental hygiene.

4. To compare pre test and post test knowledge of middle school children regarding Dental hygiene.

5. To find out the association between knowledge of middle school children regarding Dental hygiene with selected socio-demographic variables.

\section{Hypothesis}

$\mathbf{H}_{1}$ : There will be significant difference in the pre test and post test knowledge score of middle school children regarding Dental hygiene.

$\mathbf{H}_{\mathbf{0}}$ : There will be significant difference in the pre test and post test knowledge score of middle school children regarding Dental hygiene.

\section{Conceptual frame work}

The frame work of the present study was based on the on Daniel L, Stufflebeam's Context, Input, Process and Product Evaluation (CIPP) Model.

\section{Materials and Methods}

The research design used in this study was pre experimental in nature. The study was conducted at Government Middle School Salempur, district Jalandhar and Government Senior Secondary School Talhan, district Jalandhar, Punjab. The simple included 60 middle school children on the basis of inclusion and exclusion criteria were selected. Non probability convenience sampling technique was used for this study. The tool used for the study was the structured knowledge questionnaire consisting of section I (Socio- demographic varriables such as age of student (years), class standard of student, gender, type of family, monthly income of family, educational status of mother and educational status of father) and section II (consisting of 30 items related to knowledge regarding dental hygiene). The content validity of structured questionnaire was ensured by submitting the tool to the experts in the field of paediatrics for content validation. Pilot study was conducted on 10 subjects (who were not included in the study) at government school Dhanowali, Jalandhar, Punjab. The reliability of tool was computed by applying split half technique and was calculated by Karl Pearson's coefficient of correlation formula, which was found 0.78 .

\section{Results And Findings}

A. Related to socio demographic varriables of the subjects

- Maximum of middle school children 26(43.34\%) were in the age group above 13 years.

- $20(33.33 \%)$ middle school children were studying in $6^{\text {th }}$ standard, 20(33.33\%) were in $7^{\text {th }}$ standard and $20(33.33 \%)$ were in $8^{\text {th }}$ standard.

- $30(50 \%)$ sample were female and 30(50\%) were male.

- Majority of sample 38(63.34\%) were belonging to nuclear family.

- Maximum number of sample $41(68.34 \%)$ belonging to those family who had $<5000$ monthly family income.

- Maximum number of mothers 23(38.33\%) of middle school children were illiterate.

- Maximum number of fathers $23(38.34 \%)$ of middle school children had educational status primary.

\section{B. Related to the pre test and post test knowledge scores of middle schoolchildren regarding dental hygiene.}




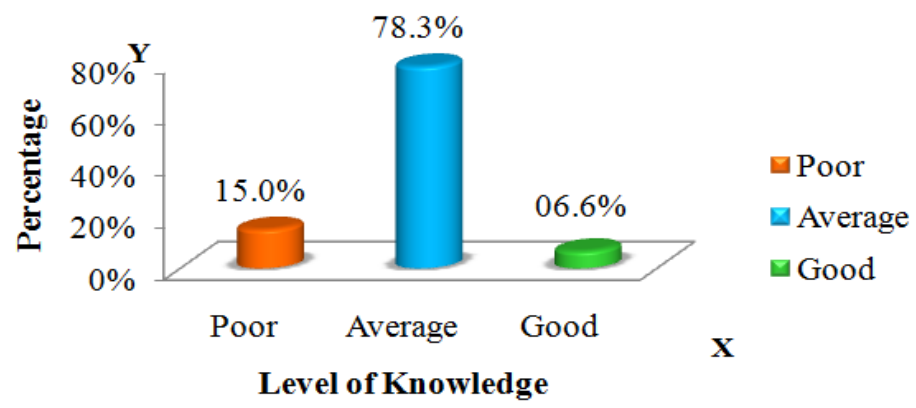

Figure 1. Pre test knowledge score of middle school children

Figure 1 shows that in pre test majority of sample 47(78.3\%) had average level of knowledge, 09(15\%) poor level of knowledge and only 04(06.6\%) had good level of knowledge regarding Dental hygiene.

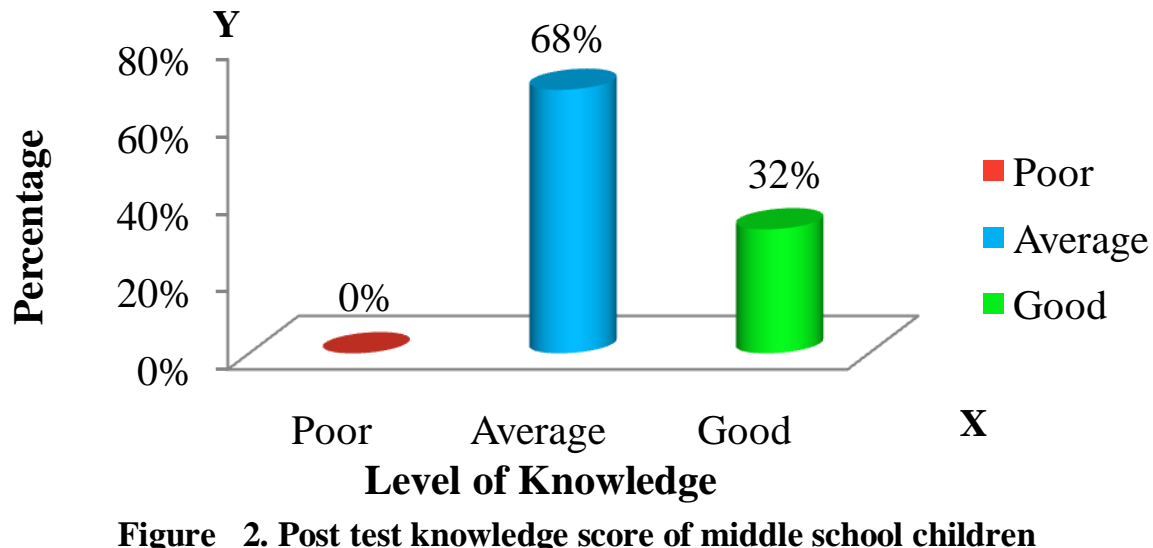

Figure 2 Shows that in post test it was observed that 41(68\%) sample had average level of knowledge, $19(32 \%)$ had good level of knowledge and no one had poor level of knowledge after administration of STP.

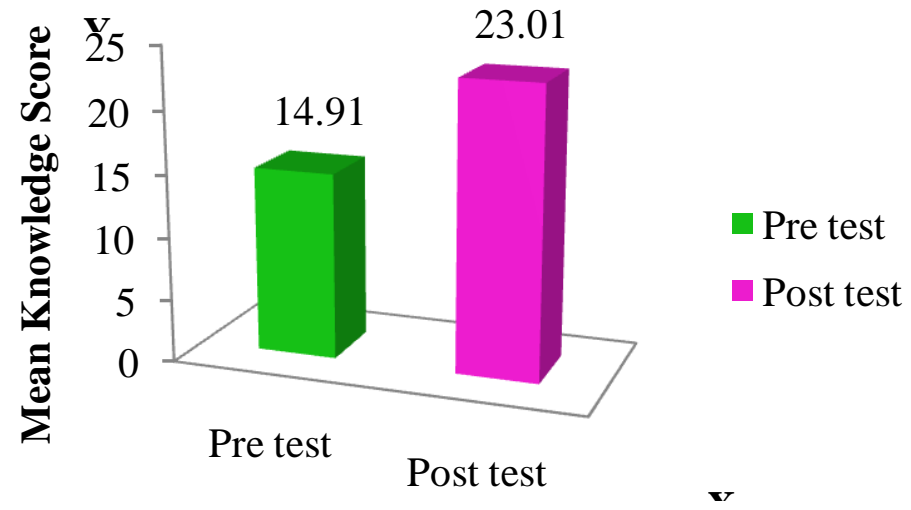

Figure 3. Comparison of pre test and post test knowledge score

Figure 3 shows that in the mean pre test knowledge score was (14.91) and post test mean knowledge score was (23.01) and. The difference between mean pre test and post test knowledge score was-8.1* significant at $\mathrm{p}<0.05$ level of significance hence there was an impact of structured teaching programme on knowledge regarding Dental hygiene.

\section{Related to the impact of Socio-demographic variables on the knowledge scores.}

The variable gender had significant association with knowledge regarding Dental hygiene among middle school children at 0.05 level of significance. But variables age of student, class standard of student, type of family, monthly income of family, educational status of mother and father had non significant association. 


\section{Nursing practice}

\section{Nursing implication}

- Nurses working in Paediatric ward should have enough knowledge about Dental hygiene of children; they should be a keen observer since the children cannot speak out their needs.

- Posters can be displayed on the importance of the correct technique of brushing and flossing in the rural areas to increase the knowledge of the community.

- Not only nurses but all the health care providers such as auxiliary nurses and midwives, village health guides, nurses working in community centre should provide in-service education regarding Dental hygiene.

\section{Nursing education}

- Nursing curriculum can be modified with increased emphasis on child health nursing.

- Students can be also trained to work in paediatric care under proper guidance.

\section{Nursing administration}

- Administrator can organise educational programmes in schools and community areas to provide knowledge regarding importance of Dental hygiene.

- The nurse administrator in the higher level of the authority must hold discussions and meetings on the prevailing Dental problems. Based on that, the knowledge of the school children can be assessed and prevention programmes can be planned and implemented in schools at various levels.

\section{Nursing research}

- The findings of the study had shown that the majority of the middle school children had inadequate level of knowledge regarding Dental hygiene. The study will motivate the beginning researchers to conduct the same study with the different variables on a large scale.

\section{Recommendations}

- The study can be repeated on the large scale sample to validate and for better generalization of the findings.

- Descriptive study can be conducted to assess knowledge, attitude and practice of school children regarding Dental hygiene.

- Comparative study may be conducted to find out the similarities or differences between the knowledge and practices of urban and rural school children.

- Regular Dental check-up may be conducted for school children.

- School syllabus may include topic related to Dental hygiene.

- Education can be given to school teachers on Dental hygiene who are the sources of knowledge for children.

\section{Conclusions}

The study findings implied that the education has a vital role in improving the knowledge of the students regarding dental hygiene. Since school education is an integral part of medical and dental services, nurses can play an important role in health educational programme, making the children an important channel for disseminating the health information to the families and the communities. Today's students are tomorrow's leaders. The student community needs to be strengthened with the treasure of knowledge especially with health related issues.

\section{References}

[1]. Peter S. Essentials of Preventive and Community Dentistry. $1^{\text {st }}$ ed. New Delhi: Arya Medical, 1999. p102.

[2]. Nair MCK, Menon PS, Parathasorthay A. IAP Textbook of Pediatrics. $2^{\text {nd }}$ ed, India: Jaypee, 2000.p.910-11.

[3]. Chandra satish. Textbook of community dentistry. $1^{\text {st }}$ ed. New Delhi: Jaypee, 2004. p.159-60, 72.

[4]. Jurgensen N, Peterson PE. Oral health and impact of socio behavioral factors in a cross section survey of 12 year old school children in Laos. BMC oral health. Nov 2009; 9: 29

[5]. Amin TT, AL Abad BM. Oral hygiene practice, knowledge, dietary habits and their relation to caries among male primary school children in Al Hassa. Indian Journal of dentistry.Nov2008; 6(4):361-70.

[6]. Polit F. Denise Hungler. Essentials of Nursing Research. $2^{\text {nd }}$ ed. JB Lippincott Company, p-117-167.

[7]. Kalawole K, Oziegde E, Bamise C. Oral hygiene measures and the periodontal status of school children in Ile-Ife. Indian Journal of dental hygiene. March 2011; $10.1601,5037$. 